\title{
The Technology of Thermal Power Plant Heating Surfaces Cleaning and Development of Facilities for its Instantiation
}

\author{
Igor E. Kimm* and Vladislav V. Azingareev \\ JSC «Krasnoyarsk Machine-building Plant» \\ Krasnoyarsk, Russian Federation
}

Received 19.11.2019, received in revised form 09.01.2020, accepted 19.02.2020

\begin{abstract}
The method of water decontamination of thermal power plant heating surfaces in the process of slag-forming fuel burning has been considered. The consequences of ash and slag formation, their influence on the boiler unit operation and the methods of elimination have been revealed. The blast by steam and water is the main and the most common cleaning method.

Despite a large number of domestic water blowers, the most part of designs has some parameters requiring their technical level improving. In order to increase the technical level of produced blowers, JSC «Krasnoyarsk machine-building plant» studies the design weaknesses based on the comments and suggestions of operation organizations. The research done allow to find out the main design parameters which can determine the reliability and efficiency of long-range water decontamination. The parameters that were defined make it possible to minimize mass, dimensions and energy consumption of the blower.

As a result of the research, a new and improved KMZE027 long-range water blower has been developed. In terms of technical specifications, it is a highly competitive machine with a foreign SMART CANNON blower by Clyde-Bergemann. Some calculations have been carried out and influence dependencies of the nozzle device design and pressure on the jet formation have been determined. The new blower is an import-substituting product. The materials and devices of domestic production are used in its design.
\end{abstract}

Keywords: blower, heating surfaces of thermal power plants, water decontamination.

Citation: Kimm I.E., Azingareev V.V. The technology of thermal power plant heating surfaces cleaning and development of facilities for its instantiation, J. Sib. Fed. Univ. Eng. \& Technol., 2020, 13(2), 233-242. DOI: 10.17516/1999-494X-0219

(C) Siberian Federal University. All rights reserved

This work is licensed under a Creative Commons Attribution-NonCommercial 4.0 International License (CC BY-NC 4.0).

* Corresponding author E-mail address: jgorkimm@yandex.ru 


\title{
Технология очистки поверхностей нагрева \\ тепловых электростанций \\ и создание технического средства ее реализации
}

\author{
И.Э. Кимм, В.В. Азингареев \\ АO «Красноярский машиностроительный завод» \\ Российская Федеращия, Красноярск
}

\begin{abstract}
Аннотация. Рассмотрено средство водяной очистки поверхностей нагрева тепловых электростанций при сжигании шлакующих топлив, выявлены последствия образования золошлаковых отложений, их влияние на работу котлоагрегата и способы устранения. Обдувка паром и водой является основным и наиболее распространенным средством очистки.

Несмотря на большое количество отечественных аппаратов водяной обдувки, большая часть конструкций имеет ряд параметров, требующих повышения их технического уровня. В целях повышения технического уровня выпускаемых аппаратов обдувки АО «Красмаш» проводит исследование недостатков их конструкции на основе замечаний и предложений эксплуатирующих организаций. Проведенные исследования позволили выявить главные конструктивные параметры, определяющие надежность и эффективность средства водяной дальнобойной очистки. Определены параметры, позволяющие максимально снизить массу, габариты и энергопотребление аппарата обдувки.

В результате проведенной работы был разработан новый модернизированный аппарат водяной обдувки дальнобойный КМЗЭ027, по техническим характеристикам не уступающий зарубежному аппарату обдува SMART CANNON фирмы Clyde-Bergemann. B процессе работы проведены расчеты и определены зависимости влияния конструкции соплового устройства и давления на формирование струи. Новый аппарат позиционируется как импортозамещающий товар, в конструкции аппарата применяются материалы и устройства отечественного производства.
\end{abstract}

Ключевые слова: аппарат обдува, поверхность нагрева тепловых электростанций, водяная очистка.

Цитирование: Кимм, И.Э. Технология очистки поверхностей нагрева тепловых электростанций и создание технического средства ее реализации / И.Э. Кимм, В.В. Азингареев // Журн. Сиб. федер. ун-та. Техника и технологии, 2020. 13(2). C. 233-242. DOI: 10.17516/1999-494X-0219

Топливно-энергетический комплекс является важнейшей отраслью мирового хозяйства. Современное мировое общество использует энергию в огромных масштабах, и размеры энергопотребления с каждым годом возрастают, что обусловлено повышением уровня жизни населения и промышленного производства.

Эффективность котлоагрегатов ТЭС (тепловая электрическая станция) зависит от наличия отложений продуктов сгорания топлива [1-3] на поверхностях нагрева (рис. 1). В области высоких температур на топочных экранах могут образовываться особенно трудноудаляемые отложения.

Зашлаковка топочной камеры приводит:

• к уменьшению КПД (коэффициент полезного действия);

- к квеличению эмиссии;

- к потере мощности; 
- к повреждению котла;

- к останову выработки тепла.

Для предотвращения указанных проблем энергетические котлы необходимо оснащать средствами очистки нагреваемых поверхностей от золошлаковых отложений, которые могли бы проводить эту работу без остановки котлов, обеспечивая необходимое условие их бесперебойной, устойчивой и надежной эксплуатации.

Аппараты ОВД (обдувки водяные дальнобойные) поддерживают эффект очистки в основном за счет термического воздействия струи на слой отложений. Динамическое воздействие играет вспомогательную роль, обеспечивая лишь более полное удаление осколков отложений (рис. 2).

Дальнобойные аппараты осуществляют обдувку противоположных стен топки без выдвижения сопловой головки в топку.

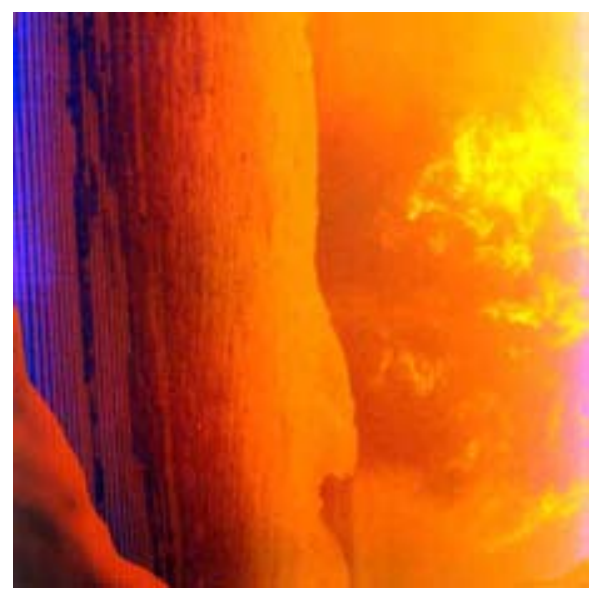

Рис. 1. Шлак в зоне горелок после длительной эксплуатации

Fig. 1. Slag in the burner area after prolonged use

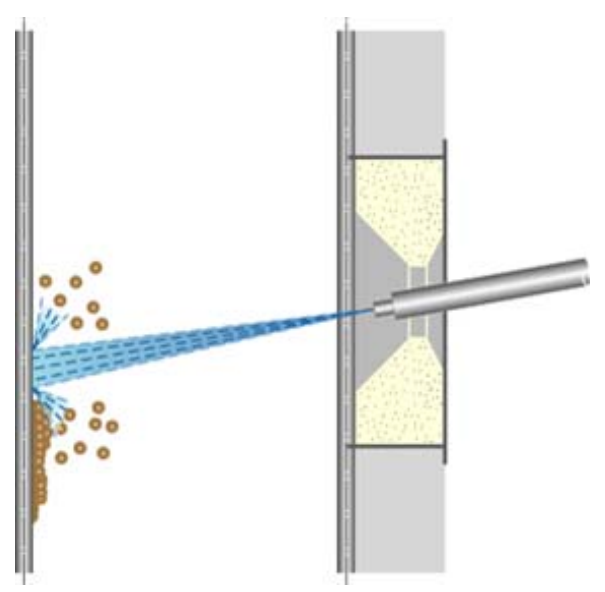

Рис. 2. Принцип очистки

Fig. 2. Cleaning principle 


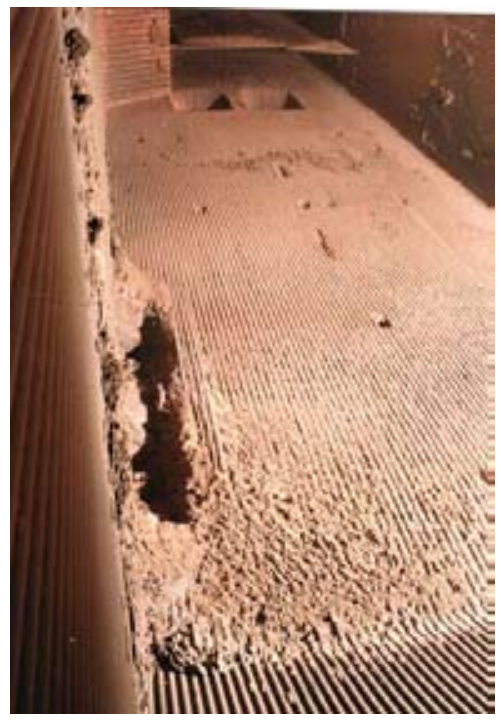

Рис. 3. Участки топочных экранов до и после водяной очистки

Fig. 3. Sections of furnace screens before and after water cleaning

Эффективность использования аппаратов ОВД общепризнана и подтверждена повсеместным практическим применением (рис. 3). Все вновь вводимые современные пылеугольные котлоагрегаты ТЭС уже на этапе проектирования оснащают системами очистки. Условия и расчеты применения аппаратов ОВД отражены в нормативном документе РД 34.27.105-90 «Meтодические указания по расчету и эксплуатации аппаратов водяной обдувки поверхностей нагрева паровых котлов».

Показатели эффективной очистки оцениваются:

- повышением воспринимаемого экранами теплового потока;

- уменьшением температуры в топке;

- уменьшением подачи питательной воды;

- уменьшением температуры уходящих газов;

- увеличением КПД котла до $1,53 \%$;

- экономией топлива.

Опыт использования показывает, что окупаемость установленных аппаратов очистки в России составляет от 1 до 4 лет.

Для обеспечения конкурентных преимуществ экономики Красноярского края по производству и поставкам аппаратов ОВД современного технического уровня краевое государственное автономное учреждение «Красноярский краевой фонд поддержки научной и научнотехнической деятельности» и АО «Красмаш» заключили в 2019 г. соглашение для реализации проекта «Создание аппарата обдувки водяного дальнобойного для очистки поверхностей нагрева энергетических котлов от шлаковых отложений».

Целью разработки является создание импортозаменяющего аппарата обдувки с программируемыми конфигурацией зон очистки, траекторией и скоростью перемещения следа струи воды по очищаемой поверхности. 
Для реализации было проведено исследование условий эксплуатации аппаратов на тепловых электростанциях, сбор и анализ требований в теплоэнергетической отрасли.

В исследовании была поставлена научно-техническая задача минимизации массы, габаритов, электропотребления аппарата с обеспечением высокого уровня технических характеристик.

Размещение аппаратов ОВД определяется устройством котлоагрегата построенного, как правило, по схеме силового металлокаркаса, на котором подвешены экранные поверхности нагрева. На силовом каркасе размещены многоуровневые площадки для обслуживания персоналом котельной оборудования. При закреплении аппарата обдува на котлоагрегате ширина прохода на площадке обслуживания уменьшается. Отсюда вытекает одно из первых требований - аппарат должен иметь возможно меньшие габариты для возможности размещения в условиях ограниченного монтажного пространства (рис. 4). Удобство проведения монтажных работ может быть значительно повышено за счет малой массы аппарата и отдельных его частей. Кроме того, поскольку аппарат крепится, как правило, к экранным поверхностям нагрева, а не на силовой металлокаркас, то малая масса аппарата снижает нагрузки на металл экранных труб, находящихся под большими температурными напряжениями.

Меньшие затраты электроэнергии ТЭС, расходуемые на работу аппаратов, при многолетней эксплуатации будут обеспечиваться меньшей мощностью установленного в аппарате электрооборудования.

Технологические процессы на котельной требуют задания траектории обдува с помощью программных средств, а не путем механического настраивания положений срабатываний путевых выключателей на аппарате вручную.

По результатам рассмотрения аппаратов ОВД в их развитии для создания современного аппарата была разработана конструкция (рис. 5), состоящая из двух модулей линейного пере-

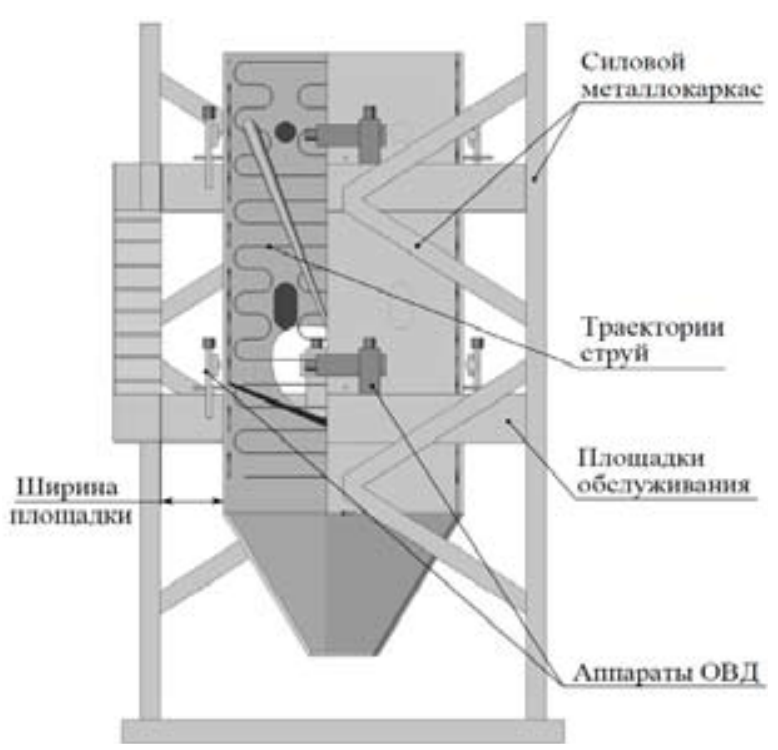

Рис. 4. Размещение аппаратов на площадках обслуживания

Fig. 4. Placement of devices on service platforms

$$
-237-
$$




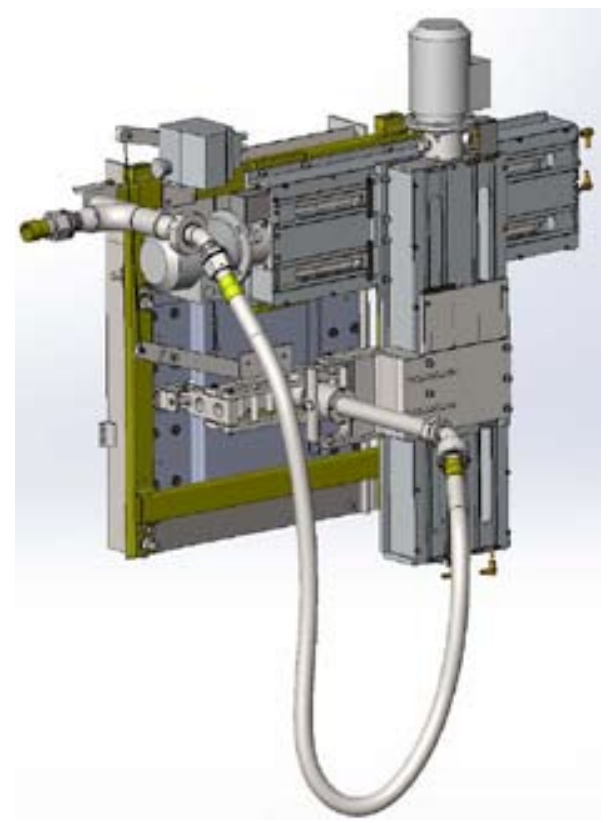

Рис. 5. Вид общий аппарата КМЗЭ027

Fig. 5. General view of the KMZ027 apparatus

мещения, приводящая в движение сопловое устройство через шарнирный механизм. Такая схема позволяет выполнять любую траекторию движения струи по очищаемой поверхности, изменять скорость струи, осуществлять одновременное движение сопла по двум координатам, исключать из траектории зоны, не требующие очистки. Переменная скорость позволяет корректировать объем воды, попадающей на зашлакованную поверхность, и избирательно регулировать степень очистки в зависимости от зашлакованности зоны.

Аппарат ОВД снабжен средствами автоматизации, что дает возможность управлять электроприводными устройствами, контролировать положение исполнительных элементов.

При проектировании аппарата были применены классические инженерные методы расчета конструкции, определяющие прочностные параметры деталей и узлов, требуемую мощность электроприводов.

Анализ нагрузок, воздействующих на аппарат, помог выделить среди множества те нагрузки, которые в решающей степени определяют массовые и энергетические характеристики аппарата, что позволило применить особые конструктивные решения в отдельных узлах аппарата для снижения возникающих при работе усилий. Было обнаружено, что лимитирующим фактором, определяющим размеры аппарата, является сопловое устройство, а точнее, условие обеспечение требуемой дальнобойности водяной струи. Оптимизация геометрических параметров гидромонитора дала возможность уменьшить размеры приводов линейного перемещения, выполняющих движение водяной струи в заданном диапазоне угловых перемещений.

Для выполнения угловых перемещений соплового устройства был применен гибкий шланг, соединяющий гидромонитор с питающим трубопроводом. При перемещении гидромонитора шланг также изменяет свои конфигурацию, положение, внутренние радиусы изгиба. Гидравли- 
ческое давление в шланге переводит материал шланга в напряженно-деформированное состояние, что увеличивает его конструктивную жесткость. Преодоление указанных сопротивлений шланга создает дополнительную нагрузку на привод линейного перемещения, вследствие чего также возрастает нагрузка на конструктивные элементы устройства, что учитывается при расчетах их жесткости и прочности, как результат - повышенные размеры и металлоемкость аппарата. Было принято решение уменьшить диаметр шланга, что позволило снизить размеры и конструктивную жесткость деталей и узлов.

Исследование частей аппарата по функциональному назначению нашло пути комплексной оптимизации конструкции аппарата, снижения себестоимости.

Сопловое устройство непосредственно формирует параметры водяной струи. В АО «Красмаш» разработан параметрический ряд сопловых устройств диаметрами от 6 до 22 мм. Для практического выбора сопла для условий конкретного котлоагрегата необходимо знание влияния параметров сопла на поведение струи.

Истечение дальнобойной водяной струи из сопла весьма сложный физико-технический процесс. Применительно к однофазной среде (распространение воздушной струи в воздушной среде) анализ выполняется на базе моделей затопленной газовой струи. Известны исследования поведения паровых и воздушных струй при их истечении из сопла [5], которые положены в основу нормативного документа РТМ 24.030.51-75 «Котлы паровые стационарные. Выбор и расчет сопловых устройств аппаратов обдувки поверхностей нагрева котельных агрегатов». Что касается двухфазной среды (распространение водяной струи в воздушной среде), имеются лишь эмпирические зависимости для дальнобойности и траектории струи, справедливые в достаточно узком диапазоне напоров, диаметров выходного отверстия и углов наклона струи $[6,7]$.

В связи с отсутствием теоретического обоснования и эмпирических моделей поведения дальнобойных водяных струй, распространяющихся в воздушной среде, использованы подходы вычислительной гидродинамики [8] с применением программного обеспечения ANSYS Fluent. К основным уравнениям математической модели относятся уравнения движения и неразрывности в форме уравнений Навье-Стокса. Вследствие больших скоростей истечения жидкости из сопла гидромонитора режим является турбулентным. Для учета турбулентности потока используется модель турбулентности SST- $k-\omega$ [9]. Взаимодействие струи воды с окружающим воздушным пространством описывается моделью двухфазного потока, в котором первая фаза представляет собой сжимаемый газ (воздух), вторая - несжимаемую жидкость (воду). Использование численного метода объема жидкости (volume of fluid) позволяет в любой момент времени определять положение поверхности раздела фаз, т.е. поверхности, ограничивающей объем воды. Дискретизация и интегрирование уравнений движения и неразрывности осуществляется численно с помощью метода конечных (контрольных) объемов. Выбирается некоторая замкнутая (расчетная) область течения жидкости или газа, для которых производится поиск полей макроскопических величин (скорости, давления...), описывающих состояние среды во времени и удовлетворяющих уравнениям Навье-Стокса. В результате получается динамическая модель струи, описывающая ее траекторию в любой момент времени, как следствие, характеристики, представляющие интерес с позиций эффективности очистки поверхностей нагрева от отложений. 


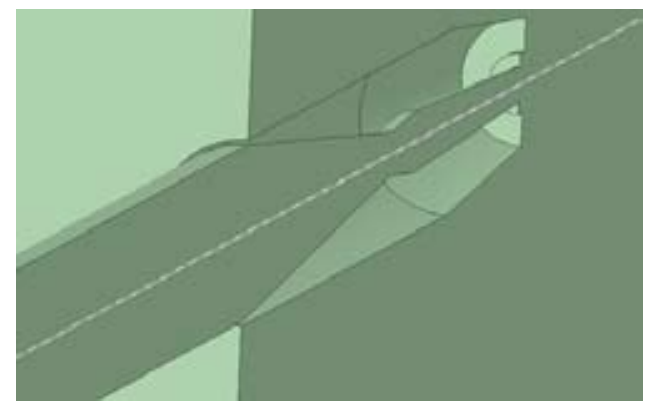

Рис. 6. Геометрическая модель входа сопла в расчетную область

Fig. 6. Geometric model of nozzle inlet to the design area

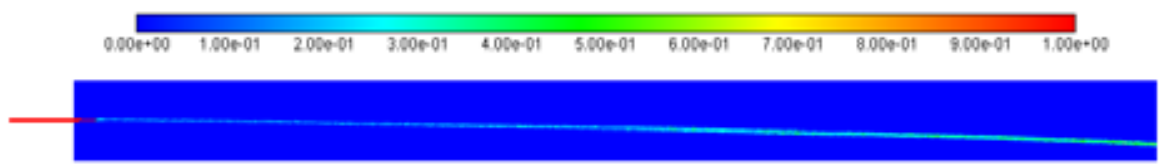

Рис. 7. Траектория струи в расчетной области

Fig. 7. Jet trajectory in the design area

На этапе разработки аппарата выполнено научно-техническое обоснование параметров струи (траектория, дальнобойность, динамический напор на дальности боя, относительный диаметр на расстоянии 100 калибров от выходного отверстия сопла) в зависимости от геометрических параметров сопла, угла его наклона и давления в магистрали. Моделирование выполнено в трехмерной постановке с учетом вертикальной плоскости симметрии (рис. 6, 7).

Перспективы дальнейшего развития техники моделирования гидромониторных струй в прикладной области разработки аппаратов обдувки водяных дальнобойных заключаются в детальном анализе поведения воды непосредственно в сопле, включая анализ влияния параметров шероховатости на характеристики турбулентности и условий возможного возникновения кавитации.

Полученные результаты моделирования следует рассматривать как информационное обеспечение для подготовки руководящего технического материала для проектных расчетов сопл аппаратов водяной обдувки.

Аппарат имеет следующие отличительные особенности:

- малая масса;

- малые габариты;

- малое энергопотребление;

- высокая компактность и дальнобойность водяной струи;

- высокая точность выполнения траектории очистки;

- выполнение траектории очистки любой конфигурации;

- высокая ремонтопригодность и оперативность в обслуживании;

- комплектующие российского производства. 
Таблица 1. Основные технические характеристики аппарата КМЗЭ027

Table 1. Main technical characteristics of the device KMZ027

\begin{tabular}{|c|l|c|}
\hline $\begin{array}{c}\text { № } \\
\text { п/п }\end{array}$ & \multicolumn{1}{|c|}{ Технические характеристики } & Значения \\
\hline & \multicolumn{1}{|c|}{ Рабочее давление воды, МПа } & $0,6-2,5$ \\
\hline & Эффективная дальнобойность, м & 35 \\
\hline & $\begin{array}{l}\text { Угол сектора обдувки аппаратом } \\
\text { очистки, градус } \\
\text { по горизонтали, тах } \\
\text { по вертикали, тах }\end{array}$ & 92 \\
\hline $\begin{array}{l}\text { Угловые скорости гидромонитора, } \\
\text { град/с : } \\
\text { по горизонтали } \\
\text { по вертикали }\end{array}$ & 92 \\
\hline & Диаметр сопла, мм & $0,7-15,7$ \\
\hline & Установленная мощность \\
в аппарате, кВт, тах & $0,7-15,7$ \\
\hline & Габариты, мм : & $6-22$ \\
\hline длина & ширина & 0,8 \\
\hline & Высота & 1270 \\
\hline & Васса, не более, кг & 1210 \\
\hline
\end{tabular}

Таким образом, на основании проведенного исследования и с учетом предложений эксплуатирующих организаций $\mathrm{AO}$ «Красмаш» разработан современный аппарат водяного обдува.

Применением результата выполненной работы станет изготовление и испытание опытного образца аппарата водяной обдувки с последующей организацией серийного выпуска аппаратов и их использование на объектах теплоэнергетики.

\section{Список литературы / References}

[1] Гаврилов А.Ф., Малкин Б.М. Загрязнение и очистка поверхностей нагрева котельных установок. М.: Энергия. 1980. 328 с. [Gavrilov A.F., Malkin B.M. Pollution and cleaning of heating surfaces of boiler plants, M.: Energiya, 1980, 328 p. (in Russian)]

[2] Кузнецов Н.В., Лужнов Г.И., Кропп Л.И. Очистка поверхностей нагрева котельных агрегатов. М.-Л.: Энергия, 1966. 272 с. [Kuznetsov N.V., Luzhnov G.I., Kropp L.I. Cleaning of heating surfaces of boiler units, M.-L.: Energiya, 1966, 272 p. (in Russian)]

[3] Лобанченко Н.Г., Гуляев М.А., Зудин Б.А. Обдувка поверхностей нагрева котельных агрегатов. М.-Л.: Госэнергоиздат, 1952. [Lubenchenko N.G., Gulyaev M.A., Zudin B.A. Blowing of heating surfaces of boiler units, M.-L.: Gosenergoizdat, 1952 (in Russian)]

[4] Васильев В.В. Исследование водяной очистки топочных экранов при сжигании бурых углей. Теплоэнергетика, 1981, 7 [Vasilyev B.B. Investigation of water purification of furnace screens during burning of brown coals, Teploenergetika, 1981, 7 (in Russian)]

$$
-241-
$$


[5] Дубовский И.Е., Песелев М.П. Исследование и расчет сопловых устройств обдувочных аппаратов. Энергомашиностроение, 1973, 10, 39-42 [Dubovsky I.E, Peselev M.P. Research and calculation of nozzle devices of blowing devices, Energomashinostroenie, 1973, 10, 39-40 (in Russian)]

[6] Вильнер Я.М., Ковалев Я.Т., Некрасов Б.Б. Справочное пособие по гидравлике, гидромашинам и гидроприводам. Под ред. Некрасова Б.Б. Минск: Вышейшая школа, 1976. 416 с. [Wilner J.M., Kovalev I.T., Nekrasov B.B. Reference manual on hydraulics, hydraulic machines and hydraulic drives, Pod redakciej Nekrasova B.B., Minsk, Vyshejshaya shkola, 1976, 416 p. (in Russian)]

[7] Абросимова Ю.Г. Гидравлика и противопожарное водоснабжение. М.: Академия ГПС МЧС России, 2003. 392 с. [Abrosimova Yu.G. Hydraulics and fire water supply, M., Akademiya GPC MCHS Russia, 2003, 293 p. (in Russian)]

[8] Волков К.Н., Емельянов В.Н. Вычислительные технологии в задачах механики жидкости и газа. М.: Физматлит, 2012. 468 c. [Volkov K.N., Emelyanov V.N. Computational technologies in fluid mechanics problems, M.: Fizmatlit, 2012, 468 p. (in Russian)]

[9] Wilcox D.C. Turbulence modeling for CFD. 1998. 537 c. 